Check for updates

Cite this: RSC Adv., 2017, 7, 40996

\section{High performance polyimides with good solubility and optical transparency formed by the introduction of alkyl and naphthalene groups into diamine monomers $\uparrow$}

\author{
Tianyun Li, ${ }^{a}$ Huahua Huang, (DD *a Lei Wang (D) $^{\mathrm{b}}$ and Yongming Chen*a
}

Three kinds of naphthalene-containing diamines with $-\mathrm{H},-\mathrm{CH}_{3}$ or $-\mathrm{CH}\left(\mathrm{CH}_{3}\right)_{2}$ substituents at the orthopositions of the aniline ring including 4,4'-(naphthalen-1-ylmethylene)dianiline (BAN-1), 4,4'(naphthalen-1-ylmethylene)bis(2,6-dimethylaniline) (BAN-2) and 4,4'-(naphthalen-1-ylmethylene)bis(2,6diisopropylaniline) (BAN-3) were synthesized via a simple one-step electrophilic substitution reaction. These diamines were then reacted with three commercial dianhydrides, via chemical imidization under microwave irradiation, to obtain nine types of polyimide (PI). It was found that the introduction of alkyl side groups can improve the solubility and optical transparency of Pls. Moreover, compared with BAN-2 based Pls containing $-\mathrm{CH}_{3}$ groups, BAN-3 based PIs containing $-\mathrm{CH}\left(\mathrm{CH}_{3}\right)_{2}$ groups exhibited better solubility and optical transparency (transmittances at $450 \mathrm{~nm}$ of over $86 \%$ ). Meanwhile, due to the presence of the rigid naphthalene side groups, all the PIs possessed high thermal stability with a glass transition temperature $\left(T_{\mathrm{g}}\right)$ of over $290{ }^{\circ} \mathrm{C}$ and a decomposition temperature at $5 \%$ weight loss of over $510{ }^{\circ} \mathrm{C}$ under nitrogen. Furthermore, the $T_{\mathrm{g}}$ of $\mathrm{PI}-2 \mathrm{~B}$ composed of $\mathrm{BAN}-2$ and $3,3^{\prime}, 4,4^{\prime}$ biphenyltetracarboxylic dianhydride (BPDA) was found to be as high as $387^{\circ} \mathrm{C}$, which is comparable to that of the commercial and conventional PI material (Kapton ${ }^{\circledR}, T_{\mathrm{g}}=390^{\circ} \mathrm{C}$ ).
Received 28th June 2017 Accepted 27th July 2017 DOI: 10.1039/c7ra07142f rsc.li/rsc-advances as methyl, ethyl and isopropyl are often introduced into the diamine or dianhydride monomers. However, the incorporation of aliphatic units generally reduces thermal stability which is a crucial factor for PIs. More and more research has been focused on the simultaneous introduction of aliphatic and aromatic units into a single monomer unit to balance the final properties of PIs, as aromatic groups such as benzene, anisole and naphthalene are rigid and helpful in improving thermal stability. ${ }^{9,10}$ Nevertheless, the reported synthetic routes for the preparation of diamines or dianhydrides containing different groups generally involved several synthetic steps, making them difficult to consider practical application. ${ }^{10}$

In recent decades, some groups have utilized a one-step reaction of aldehyde I and aniline II, catalyzed by strong protonic acids, to prepare various diamines with side groups as shown in Scheme 1. ${ }^{6,11,12}$ Using this reaction pathway, it is relatively easy to introduce various aliphatic units into the $\mathrm{R}^{2}$ and $\mathrm{R}^{3}$ positions and aromatic units into $\mathrm{R}^{1}$ position of the diamine. Moreover, most of the aldehydes and anilines are commercially available and relatively inexpensive. It is therefore anticipated that this synthetic route to diamines containing side groups could be extremely useful in the development of high performance PIs of low-cost. Sarojadevi, ${ }^{13} \mathrm{Huang}^{14}$ and Li group $s^{15}$ have previously used this reaction to prepare various diamines, discovering that most of the resulting PIs were 


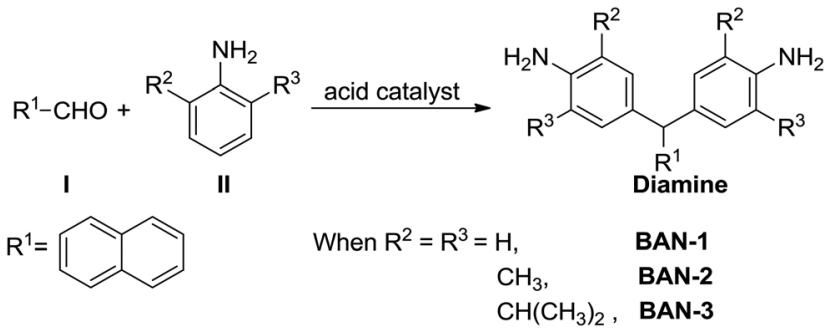

Scheme 1 Synthetic route of diamine monomer via a one-step reaction of aldehyde I and aniline II.

soluble in common organic solvents. However, some PIs were found to still exhibit deep color. Furthermore, the glass transition temperature $\left(T_{\mathrm{g}}\right)$ of these PIs was much lower than that of commercial PI (Kapton $\circledast, T_{\mathrm{g}}=390^{\circ} \mathrm{C}$ ). Cheng et al. studied the effect of $\mathrm{R}^{2}$ and $\mathrm{R}^{3}$ groups on the thermal properties of PIs and found that methyl groups at the ortho-positions of the aniline ring can increase the $T_{\mathrm{g}}$ of PIs. This was because the introduced methyl group can hinder rotation of the two aromatic rings around the $\mathrm{C}-\mathrm{N}$ bond. Nevertheless, they did not introduce an aromatic group into the $\mathrm{R}^{1}$ position, and the $T_{\mathrm{g}}$ of the resulting PIs was not high enough. ${ }^{16}$ Meanwhile, it remained unclear how the $\mathrm{R}^{2}$ and $\mathrm{R}^{3}$ alkyl groups of diamines affected the solubility and optical transparency of PIs.

In this paper, we prepare three different diamines whose $\mathrm{R}^{2}$ and $\mathrm{R}^{3}$ groups are $-\mathrm{H},-\mathrm{CH}_{3}$ and $-\mathrm{CH}\left(\mathrm{CH}_{3}\right)_{2}$ via a simple onestep reaction of aldehyde I and aniline II (Scheme 1). Our main purpose was to investigate how alkyl groups at the orthopositions of the aniline ring affected the solubility and optical transparency of PIs. Meanwhile, naphthalene was used as the $\mathrm{R}^{1}$ group because this group is known to enhance the solubility and thermal stability of materials. ${ }^{7,13}$ The diamines were reacted with three commercial dianhydrides including 4,4'-oxydiphthalic anhydride (ODPA), BPDA and $\left(4,4^{\prime}\right.$-hexafluoroisopropylidene)-diphthalic anhydride (6FDA) via a onestep microwave assisted method to yield a series of PI films as shown in Scheme 2. The solubility, transparency, thermal stability and mechanical properties of these PIs were studied.

\section{Experimental}

\section{Materials}

ODPA (98\%), BPDA (98\%) and 6FDA (98\%) were purchased from TCI and dried at $120{ }^{\circ} \mathrm{C}$ for 1 day under vacuum prior to use. 1-Naphthaldehyde (97\%), aniline (99\%), 2,6-dimethylaniline (99\%), 2,6-diisopropylaniline, $m$-cresol (99\%), isoquinoline (98\%) and triethylamine (99\%) were purchased from Aladdin and used as received. Sulfuric acid (98\%), concentrated hydrochloric acid, sodium hydroxide (AR) and 1-methyl-2pyrrolidinone (NMP, 98\%) were purchased from Aladdin. Other solvents including $N, N^{\prime}$-dimethylacetamide (DMAc), $N, N^{\prime}$ dimethylformamide (DMF), tetrahydrofuran (THF), dichloromethane $\left(\mathrm{CH}_{2} \mathrm{Cl}_{2}\right)$, chloroform $\left(\mathrm{CHCl}_{3}\right)$ and dimethyl sulfoxide (DMSO) were chemical pure grade from Guangzhou Chemical Reagent Factory and used as received.

\section{Characterization}

NMR spectra were recorded on a Bruker Avance 400 spectrometer at resonant frequencies of $400 \mathrm{MHz}$ for ${ }^{1} \mathrm{H}$ and $100 \mathrm{MHz}$ for ${ }^{13} \mathrm{C}$ nuclei using DMSO- $d_{6}$ or $\mathrm{CDCl}_{3}$ as the solvent. Elemental analysis was performed on a CHNS element analyzer. Melting points were obtained on a polarizing microscope (Shang Hai SGW X-4). The PIs were synthesized by microwave-assisted polymerization with a microwave synthesizer using Biotage Initiator $^{+}$instrument. Fourier-transform infrared spectra (FT-IR) and attenuated total reflection Fourier-transform infrared spectra (ATR FT-IR) were measured on a Bruker Vector 22 spectrometer in the range of $400-4000 \mathrm{~cm}^{-1}$. Inherent viscosities were performed with an Ubbelohde viscometer placed in water at $35{ }^{\circ} \mathrm{C}$ after the PI was dissolved in NMP completely. The number-average molecular weight $\left(M_{\mathrm{n}}\right)$ and polydispersity index (PDI) were tested by gel permeation chromatography (GPC) on a Waters equipped with a set of Waters

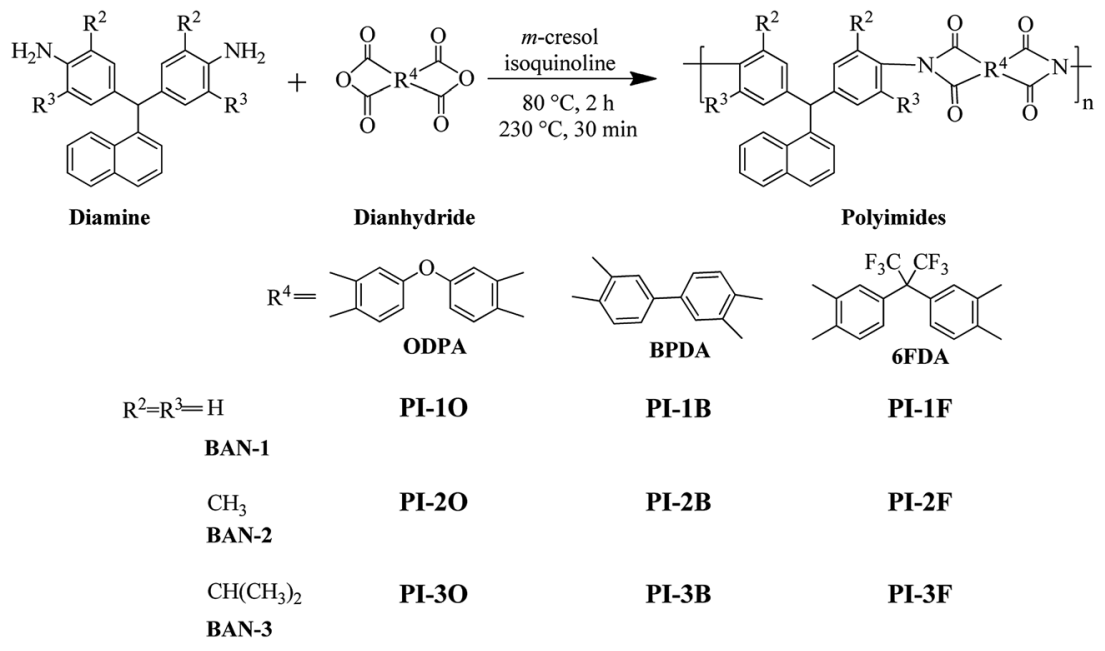

Scheme 2 Synthetic route of naphthalene-containing Pls. 
Styragel HT-2, HT-4 and HT-6 columns, monitored by 2414 refractive index detectors. The columns were maintained at $50{ }^{\circ} \mathrm{C}$ in an oven. DMF containing $0.01 \mathrm{M}$ lithium bromide was

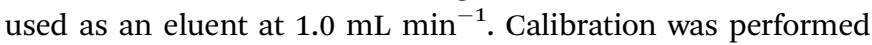
using polystyrene as standards. Wide-angle X-ray diffraction (WXRD) patterns were obtained with a RIGAKU D-MAX 2200 VPC, using graphite monochromated $\mathrm{Cu} \mathrm{K} \alpha$ radiation $(\lambda=1.5418 \AA)$ and a $0.5 \mathrm{~mm}$ collimator at room temperature.

The thermal decomposition behaviors were recorded by thermogravimetric analysis (TGA) under $\mathrm{N}_{2}$ using Pyris TG 2000 equipment with about $3-5 \mathrm{mg}$ of film sample at a heating rate of $10{ }^{\circ} \mathrm{C} \mathrm{min}^{-1}$. Measurements of $T_{\mathrm{g}}$ were performed by differential scanning calorimetry (DSC) using a PerkinElmer DSC-7 instrument with a heating rate of $20{ }^{\circ} \mathrm{C} \mathrm{min}{ }^{-1}$ under $\mathrm{N}_{2}$ from 40 to $400{ }^{\circ} \mathrm{C}$. The thickness of films was measured by digital display thickness gauge (exploit 220200, the resolution was $1 \mu \mathrm{m}$ ). The coefficients of thermal expansion (CTEs) were conducted by thermo mechanical analysis (TMA) using TA Q400 equipment with a heating rate of $10^{\circ} \mathrm{C} \mathrm{min}^{-1}$ in the range from 100 to $200{ }^{\circ} \mathrm{C}$. Ultraviolet-visible (UV-vis) spectra of the films (about $20 \mu \mathrm{m}$ ) were evaluated by a Thermo Evolution 201 spectrometer in transmittance mode, with spectrometer width of $200-800 \mathrm{~nm}$ at room temperature. Tensile properties were measured with universal testing measurement (UTM) of Xinsansi Company. Materials were tested with $4 \mathrm{~mm} \times 25 \mathrm{~mm}$ at a strain rate of $10 \mathrm{~mm} \mathrm{~min}^{-1}$ at room temperature and the minimal strength was $50 \mathrm{~N}$.

\section{Monomer synthesis}

Synthesis of BAN-1 and BAN-2. The two monomers BAN-1 and BAN-2 were synthesized via a reaction between 1-naphthaldehyde and aniline or 2,6-dimethylaniline, respectively, according to the methodology in the literature. ${ }^{17}$ Elemental analysis: calc. for $\mathrm{C}_{23} \mathrm{H}_{20} \mathrm{~N}_{2}$ of BAN-1: C, 85.2; H, 6.2; N, 8.6\%. Found: C, 84.9; H, 5.9; N, 8.8\%. Calc. for $\mathrm{C}_{27} \mathrm{H}_{28} \mathrm{~N}_{2}$ of BAN-2: C, 85.2; H, 7.4; N, 7.4\%. Found: C, 85.1; H, 7.5; N, 7.5\%.

Synthesis of BAN-3. A $250 \mathrm{~mL}$ three-neck flask equipped with a reflux condenser was charged with 2,6-diisopropylaniline (22.33 g, $126 \mathrm{mmol})$, 1-naphthaldehyde $(7.80 \mathrm{~g}, 50 \mathrm{mmol})$, concentrated sulfuric acid $(16 \mathrm{~mL})$ and deionized $\mathrm{H}_{2} \mathrm{O}(100 \mathrm{~mL})$. The reaction system was stirred at $100{ }^{\circ} \mathrm{C}$ under a nitrogen atmosphere for $20 \mathrm{~h}$ during which a yellow solid was formed. An aqueous solution of sodium hydroxide ( $60 \mathrm{~mL}, 20 \mathrm{wt} \%$ ) was added to the resulting suspension when the reaction mixture had cooled to $60{ }^{\circ} \mathrm{C}$. The mixture was poured into deionized $\mathrm{H}_{2} \mathrm{O}$ and stirred for 5 hours. A pale yellow solid was filtered and washed repeatedly with deionized $\mathrm{H}_{2} \mathrm{O}$. The product was recrystallized from methanol to produce white crystals. Yield: $11.32 \mathrm{~g}, 46 \%$. Melting point: $174-175{ }^{\circ} \mathrm{C}$. Elemental analysis: calc. for $\mathrm{C}_{35} \mathrm{H}_{44} \mathrm{~N}_{2}$ : C, 85.3; H, 9.0; N, 5.7\%. Found: C, 85.4; H, 9.0; N, 5.6\%.

\section{Polymer synthesis}

All PIs were synthesized via chemical imidization under microwave irradiation. A typical synthetic procedure of PI-1O is demonstrated as follows: two monomers BAN-1 (0.6488 g, $2.0 \mathrm{mmol})$ and ODPA (0.6226 $\mathrm{g}, 2.02 \mathrm{mmol})$, isoquinoline (ca. 5 drops) and $5 \mathrm{~mL}$ of $m$-cresol were added to a unique tube used for microwave reaction, and then sealed. The solid content of the reaction system was about $20 \mathrm{wt} \%$. All operations were completed inside a glovebox purged with nitrogen before the reaction. The homogeneous mixture was irradiated at $80^{\circ} \mathrm{C}$ for $2 \mathrm{~h}, 230{ }^{\circ} \mathrm{C}$ for $30 \mathrm{~min}$ and a yellow and transparent viscous liquid was obtained. After cooling to room temperature, the solution was diluted with $\mathrm{CHCl}_{3}$ and slowly poured into an excess of ethanol. Pure PI-1O was obtained by repeating the reprecipitation from $\mathrm{CHCl}_{3}$ into ethanol and drying at $80{ }^{\circ} \mathrm{C}$ under vacuum. The PIs based on BAN-3 were prepared with a similar experimental procedure to those of the PIs based on BAN-1 and BAN-2, except that the catalyst was triethylamine.

\section{Film preparation}

The PI powder was firstly dissolved in DMAc with the content of about $10 \%\left(\mathrm{w} / \mathrm{v}, \mathrm{g} \mathrm{mL}^{-1}\right)$ and then filtered through a $0.45 \mu \mathrm{m}$ PTFE filter. After casting onto clean glass plates, the solution was heated at $60{ }^{\circ} \mathrm{C}$ for $12 \mathrm{~h}$ and $200{ }^{\circ} \mathrm{C}$ for $12 \mathrm{~h}$ under vacuum to thoroughly remove the solvent. TGA (Pyris TG 2000) was used to confirm that the dried film contained no residual solvent. It is worth mentioning that NMP was used to dissolve PI-1B as it cannot be dissolved in DMAc.

\section{Results and discussion}

\section{Synthesis and characterization of diamines}

Three kinds of naphthalene-containing diamines, including BAN-1, BAN-2 and BAN-3, were synthesized to study the influence of aliphatic groups at the ortho-positions of the aniline ring on the physical properties of PIs. All three compounds were prepared through a one-step electrophilic substitution reaction of aldehyde I and aniline II, as shown in Scheme 1. After the reaction, recrystallization was used to purify BAN-3 while a simple precipitation was used to purify BAN-1 and BAN-2. The three diamines were tested by ${ }^{1} \mathrm{H}$ and ${ }^{13} \mathrm{C} \mathrm{NMR}$, which are provided in ESI (Fig. S1 and $\mathrm{S} 2 \dagger$ ). All spectral data of the monomers were in accordance with their molecular structures.

Table 1 Inherent viscosities and molecular weights of naphthalenecontaining PIs

\begin{tabular}{llll}
\hline PIs & $\eta_{\text {inh }}{ }^{a}\left(\mathrm{dL} \mathrm{g}^{-1}\right)$ & $M_{\mathrm{n}}{ }^{b}\left(\times 10^{4} \mathrm{~g} \mathrm{~mol}^{-1}\right)$ & PDI \\
\hline PI-1O & 0.67 & $c$ & $c$ \\
PI-2O & 0.99 & 19.18 & 1.44 \\
PI-3O & 0.61 & 9.57 & 1.46 \\
PI-1F & 0.54 & $c$ & $c$ \\
PI-2F & 0.87 & $c$ & $c$ \\
PI-3F & 0.78 & 13.35 & 1.44 \\
PI-1B & 0.66 & $d$ & $d$ \\
PI-2B & 1.03 & $c$ & $c$ \\
PI-3B & 0.68 & 9.18 & 1.34
\end{tabular}

${ }^{a}$ Measured at PI concentration of $0.5 \mathrm{~g} \mathrm{dL}^{-1}$ in NMP at $35{ }^{\circ} \mathrm{C}$. ${ }^{b}$ Measured by GPC in DMF. ${ }^{c}$ There was no GPC peak of PI sample. ${ }^{d}$ The PI did not dissolve in DMF. 


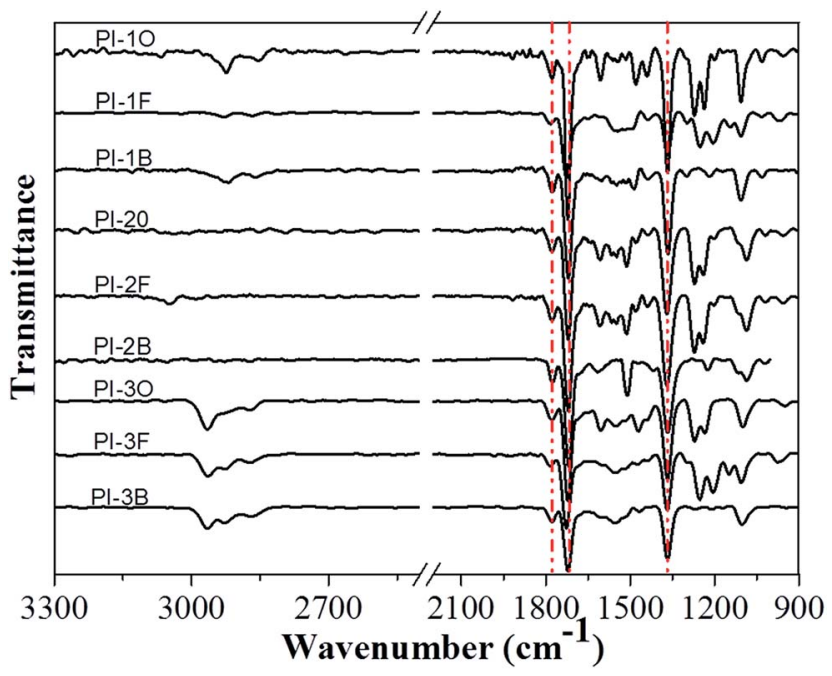

Fig. 1 ATR FT-IR spectra of all naphthalene-containing PI films.

\section{Synthesis and characterization of naphthalene-containing PIs}

Recently, microwave-assisted polymerizations are being frequently adopted as compared with conventional heating, microwave reactions have obvious advantages such as shorter reaction time, reduced side reactions and higher yields. ${ }^{\mathbf{1 8}}$ Nevertheless, report on microwave-assisted polymerization of PIs remain relatively unusual. Herein, all polymerizations of naphthalene-containing PIs were carried out using a Biotage ${ }^{\circledR}$ Initiator $^{+}$synthesizer in a sealed tube. The diamines, dianhydrides, $m$-cresol solvent and isoquinoline or triethylamine catalyst were added to the reaction tube together under nitrogen inside a glove box. The monomer contents were $20-25 \mathrm{wt} \%$. The reaction tube was heated at $60-80{ }^{\circ} \mathrm{C}$ for $2 \mathrm{~h}$ to form poly(amic acid) (PAA), then at $240{ }^{\circ} \mathrm{C}$ for $30 \mathrm{~min}$ for chemical imidization under stirring in the microwave reactor. The yields of all PI products were higher than $90 \%$.
The inherent viscosity of all PIs was measured in NMP solvent at $35{ }^{\circ} \mathrm{C}$, and the result listed in Table 1 . It was found that the inherent viscosities $\left(\eta_{\text {inh }}\right)$ of all PIs were rather high and more than $0.6 \mathrm{dL} \mathrm{g}^{-1}$, except for PI-1F. Moreover, the $\eta_{\text {inh }}$ values of BAN-2 series PIs were obviously higher than those of BAN-1 and BAN-3 based PIs with the same dianhydride. This should be due to the electronic effects of the methyl groups at the orthopositions of the aniline ring, which can enhance the nucleophilic activity of the amino unit, thus increasing the reactivity of BAN-2. Additionally, it was discovered that the $\eta_{\text {inh }}$ value $\left(0.87 \mathrm{dL} \mathrm{g}^{-1}\right)$ of PI-2F was higher than that of PI composed of the same monomer prepared by conventional heating within the literature $\left(0.54 \mathrm{dL} \mathrm{g}^{-1}\right){ }^{19}$ This may be related to microwaveassisted polymerization, which is favorable in increasing the molecular weight of polymers. The molecular weights of some PIs can be characterized by GPC. It was found that the samples had a high $M_{\mathrm{n}}$ ranging from $9.18 \times 10^{4}$ to $19.18 \times 10^{4} \mathrm{~g} \mathrm{~mol}^{-1}$, as well as a relatively small PDI (lower than 1.50) (Table 1). It is worth noting that some PIs such as PI-1O and PI-1F had no GPC peak. This means that the polymers cannot be eluted from the columns of GPC probably due to the strong interaction between polymers and the columns.

The chemical structures of naphthalene-containing PIs were confirmed by ATR FT-IR and NMR spectra. Fig. 1 presents the ATR FT-IR spectra of all the PIs. Typical absorption bands of imide groups appeared at $1778 \mathrm{~cm}^{-1}(\mathrm{C}=\mathrm{O}$ asymmetrical stretching), $1727 \mathrm{~cm}^{-1}(\mathrm{C}=\mathrm{O}$ symmetrical stretching) and $1365 \mathrm{~cm}^{-1}$ (C-N stretching), which reflected the formation of the imide structure. Meanwhile, the characteristic absorptions of amide groups in the region of $3220-3440 \mathrm{~cm}^{-1}(\mathrm{~N}-\mathrm{H}$ stretching) were no longer detectable, clearly indicating that all the PIs had been fully imidized.

All the PIs were characterized by ${ }^{1} \mathrm{H}$ NMR spectra using $\mathrm{CDCl}_{3}$ as solvent except for PI-1B (BAN-1/BPDA) polymer, due to poor solubility. Fig. 2 showed the ${ }^{1} \mathrm{H}$ NMR spectrum of PI-3O. The proton signals of the isopropyl side group were observed in the upfield region of $0.96 \mathrm{ppm}$ and $2.67 \mathrm{ppm}$. The signal of
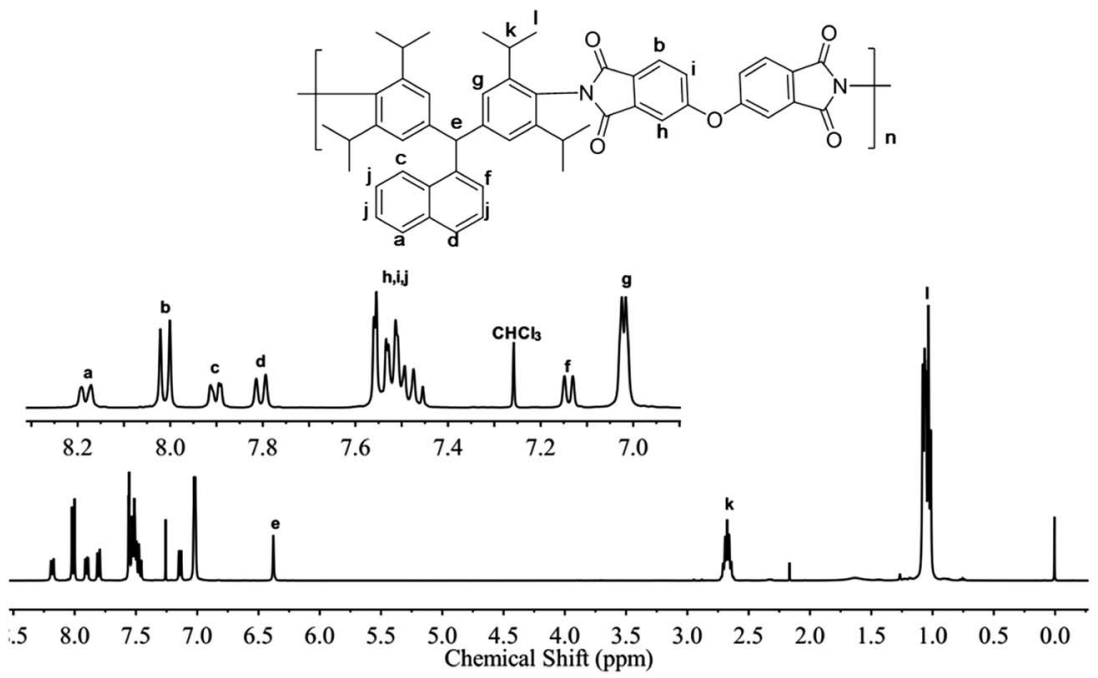

Fig. $2{ }^{1} \mathrm{H}$ NMR spectrum of PI-30 polymer $\left(\mathrm{CDCl}_{3}, 400 \mathrm{MHz}\right)$. 


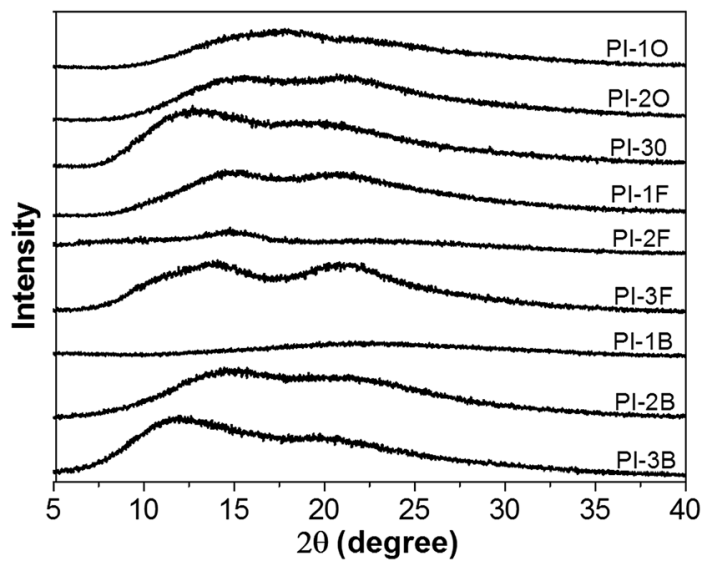

Fig. 3 X-ray diffraction profiles of naphthalene-containing PI films.

the $\mathrm{CH}$ group of the backbone was located at $6.25 \mathrm{ppm}$, and the signals of the phenyl and naphthalene protons appeared in the downfield region ranging from $7.02 \mathrm{ppm}$ to $8.27 \mathrm{ppm}$. Additionally, as shown in the ${ }^{13} \mathrm{C}$ NMR spectrum of PI-3O (Fig. S3 $\dagger$ ), a very strong imide carbon peak appeared at $165 \mathrm{ppm}$, while a carboxylic peak at approximately $200 \mathrm{ppm}$ was not detectable, also confirming complete imidization reaction. ${ }^{1} \mathrm{H}$ NMR spectra of other PIs are offered in Fig. S4-S6. $\dagger$ All the spectral data of the PIs matched with the expected structure of the PI polymers.

The morphology of naphthalene-containing PI films (thickness of around $20 \mu \mathrm{m}$ ) was studied by X-ray diffractometer and the diffraction spectra displayed in Fig. 3. In their X-ray diffraction curves, there are no sharp scattering signals and only very broad peaks, which reflect that all the PI films exhibit amorphous patterns. This indicated that the naphthalene and aliphatic pendant groups at the ortho-positions of the aniline ring disturbed the well-packed PI chains and decreased the packing density.

\section{Solubility of naphthalene-containing PIs}

The solubility of all the PIs was tested by dissolving PI films in common organic solvents with a concentration of $10 \mathrm{mg} \mathrm{mL}^{-1}$, and the results collected in Table 2. Two series of PIs composed

Table 2 Solubility of naphthalene-containing PI films ${ }^{a}$

\begin{tabular}{llllllllll}
\hline PIs & $m$-Cresol & NMP & DMSO & DMAc & $\mathrm{CH}_{2} \mathrm{Cl}_{2}$ & $\mathrm{CHCl}_{3}$ & $\mathrm{THF}$ & Acetone \\
\hline PI-1O & ++ & + & + & ++ & ++ & ++ & +- & - \\
$\mathrm{PI}-2 \mathrm{O}$ & ++ & ++ & + & ++ & ++ & ++ & ++ & - \\
$\mathrm{PI}-3 \mathrm{O}$ & ++ & ++ & + & ++ & ++ & ++ & ++ & +- \\
$\mathrm{PI}-1 \mathrm{~F}$ & ++ & ++ & + & ++ & ++ & ++ & ++ & +- \\
$\mathrm{PI}-2 \mathrm{~F}$ & ++ & ++ & + & ++ & ++ & ++ & ++ & +- \\
$\mathrm{PI}-3 \mathrm{~F}$ & ++ & ++ & + & ++ & ++ & ++ & ++ & ++ \\
$\mathrm{PI}-1 \mathrm{~B}$ & ++ & ++ & +- & +- & +- & +- & +- & - \\
$\mathrm{PI}-2 \mathrm{~B}$ & ++ & ++ & +- & + & + & ++ & +- & - \\
$\mathrm{PI}-3 \mathrm{~B}$ & ++ & ++ & +- & ++ & ++ & ++ & ++ & +-
\end{tabular}

${ }^{a}++$ : soluble at room temperature; + : soluble upon heating at $100{ }^{\circ} \mathrm{C}$; +- : partially soluble upon heating at $100{ }^{\circ} \mathrm{C}$ or the boiling point; -: insoluble upon heating. Solubility was measured with the concentration of $10 \mathrm{mg} \mathrm{mL} \mathrm{mL}^{-1}$ for $24 \mathrm{~h}$. of ODPA or 6FDA dianhydride are not only soluble in polar solvents such as $m$-cresol, NMP, DMSO and DMAc, but are also soluble in solvents of low boiling point like $\mathrm{CH}_{2} \mathrm{Cl}_{2}$ and $\mathrm{CHCl}_{3}$, at room temperature or upon heating. It was additionally found that PI-2O and PI-3O are soluble in non-polar THF solvent at room temperature, but that PI-1O is only partially soluble in THF even upon heating to reflux. These results reflect that the introduction of side groups at the ortho-positions of the imide ring can enhance the solubility of PIs. When rigid BDPA dianhydride is used, the side group of the diamines also has a great effect on the solubility of PIs. PI-1B is only able to be soluble in $m$-cresol and NMP, while PI-2B and PI-3B are soluble in some solvents of low boiling point.

Furthermore, compared with the solubility of PIs composed of the same dianhydride in acetone, it was clearly found that the solubility of PIs with BAN-3 was better than that of PIs with BAN-1 or BAN-2 diamine. This indicates that an isopropyl group is more beneficial than a methyl group for the solubility of PIs, presumably because the free volume of the PI polymeric chains is increased due to the bulky isopropyl unit. Thereof, the ability of the diamines to improve the solubility of PIs follows the order: BAN-3 > BAN-2 > BAN-1. As thus, PI-3F polymer composed of BAN3 and 6FDA has the most optimal solubility of our system owing to the presence of two bulky isopropyl and $\mathrm{CF}_{3}$ groups, leading to an efficient reduction of the interactions among polymeric chains.

\section{Thermal properties of naphthalene-containing PIs}

Thermal properties of PIs including $T_{\mathrm{g}}$, thermal decomposition and CTE were evaluated by DSC, TGA and TMA, respectively, and the data summarized in Table 3. Fig. 4 and 5 display TGA curves and DSC second heating scan curves of all PI films, respectively.

As shown in Table 3, the decomposition temperatures of all PIs at $5 \%$ and $10 \%$ weight loss $\left(T_{\mathrm{d} 5}\right.$ and $\left.T_{\mathrm{d} 10}\right)$ are over 510 and $525{ }^{\circ} \mathrm{C}$, respectively. Meanwhile, the PIs have high char yields $(>55 \%)$. These results firmly indicate that all the PIs possess excellent thermal stability, regardless of the aliphatic substituent used in the system. In previous literature based on similar PIs with methylbenzene, tert-butyl benzene, morpholinyl or anthracene as the pendant substituents, the $T_{\mathrm{d} 10}$ data of the PIs

Table 3 Thermal properties of naphthalene-containing PI films

\begin{tabular}{llllll}
\hline PIs & $T_{\mathrm{d} 5}{ }^{a}\left({ }^{\circ} \mathrm{C}\right)$ & $T_{\mathrm{d} 10}{ }^{a}\left({ }^{\circ} \mathrm{C}\right)$ & $R_{\mathrm{w}}{ }^{b}(\%)$ & $T_{\mathrm{g}}{ }^{c}\left({ }^{\circ} \mathrm{C}\right)$ & $\mathrm{CTE}^{d}\left(\mathrm{ppm}^{\circ} \mathrm{C}^{-1}\right)$ \\
\hline PI-1O & 523 & 539 & 55 & 301 & 56.50 \\
PI-2O & 528 & 540 & 63 & 343 & 56.10 \\
PI-3O & 516 & 528 & 56 & 296 & 75.23 \\
PI-1F & 519 & 532 & 59 & 322 & 54.30 \\
PI-2F & 536 & 555 & 64 & 343 & 52.40 \\
PI-3F & 511 & 526 & 60 & 294 & 83.10 \\
PI-1B & 538 & 555 & 63 & 341 & 52.10 \\
PI-2B & 550 & 567 & 68 & 387 & 48.03 \\
PI-3B & 526 & 542 & 65 & 339 & 65.68
\end{tabular}

${ }^{a}$ Temperature at $5 \%$ and $10 \%$ weight loss determined by TGA with $10{ }^{\circ} \mathrm{C}$ min $^{-1}$ under nitrogen. ${ }^{b}$ Residual weight percentage at $800{ }^{\circ} \mathrm{C}$. ${ }^{c}$ Measured by DSC with $20{ }^{\circ} \mathrm{C} \mathrm{min}^{-1}$. ${ }^{d}$ Measured by TMA from 50 to $200{ }^{\circ} \mathrm{C}$ with $10{ }^{\circ} \mathrm{C} \mathrm{min}^{-1}$. 


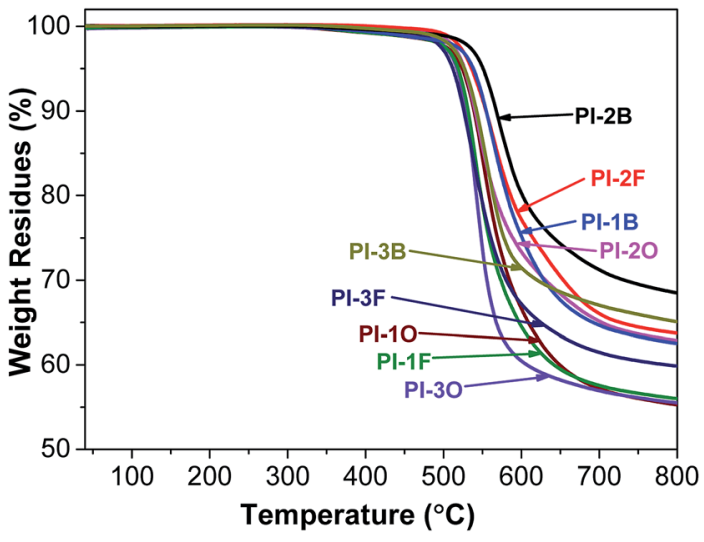

Fig. 4 TGA curves of naphthalene-containing PI films.

were less than $500{ }^{\circ} \mathrm{C} .{ }^{11,12,20}$ This indicates that the use of stiff and aromatic naphthalene as a pendant group can enhance the thermal properties of PIs. Additionally, it was discovered that the $T_{\mathrm{d} 5}$ and $T_{\mathrm{d} 10}$ data of BAN-2 based PIs are higher than those of BAN-1 and BAN-3 based PIs when the same dianhydride is used. This indicates that the methyl substituent can increase the thermal stability of PIs. This is because a methyl group at the ortho-position of the imide nitrogen limits the rotation of the $\mathrm{C}-\mathrm{N}$ bond, thus leading to increase rigidity within the molecular chains. However, the isopropyl group of relatively large steric hindrance would weaken the intermolecular interaction of PI chains. Thus, the thermal stability of naphthalenecontaining PIs follows this order: BAN-2 > BAN-1 > BAN-3.

The $T_{\mathrm{g}}$ values of the PIs was discovered to be in line with the decomposition data. BAN-2 based PI showed the highest $T_{\mathrm{g}}$ value, while BAN-3 based PI exhibited the lowest value when compared with PIs of the same dianhydride. All the $T_{\mathrm{g}}$ data of BAN-2 based PI series are over $340{ }^{\circ} \mathrm{C}$, even in the presence of a flexible ether bond in the PI-2O backbone. Moreover, PI-2B composed of BAN-2 diamine and a stiff BPDA dianhydride exhibits an especially high $T_{\mathrm{g}}$ value $\left(387^{\circ} \mathrm{C}\right)$, comparable to that of the commercial and fully

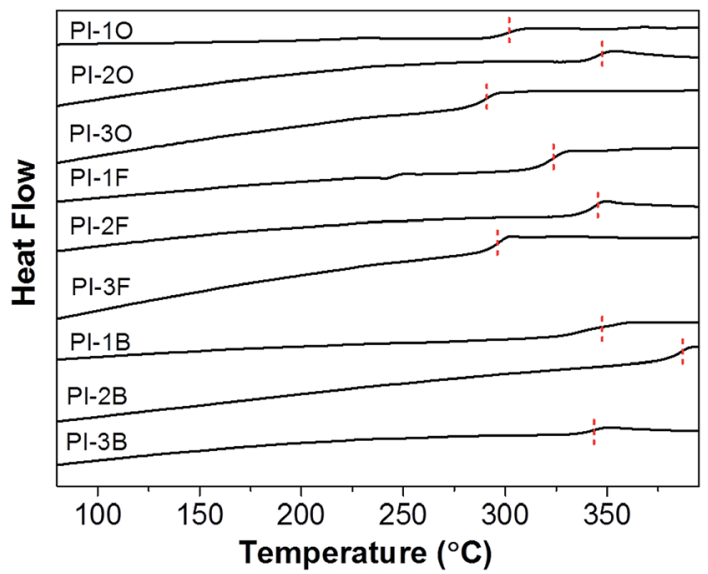

Fig. 5 DSC second heating scan curves of naphthalene-containing PI films with $20{ }^{\circ} \mathrm{C} \mathrm{min}^{-1}$.

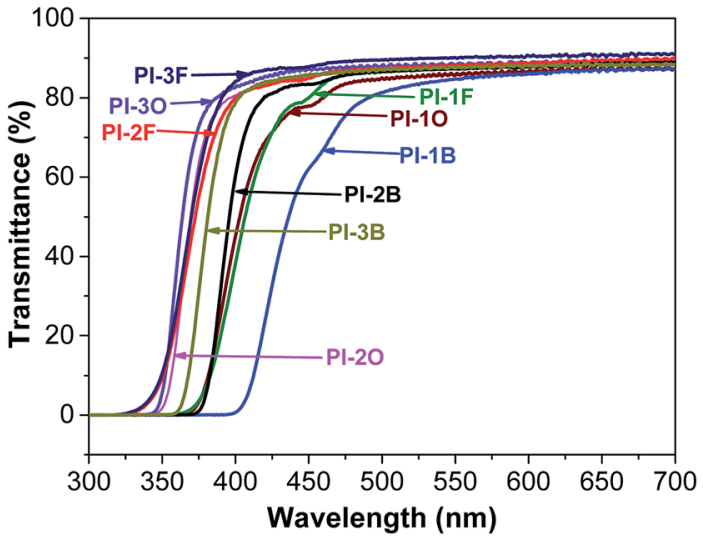

Fig. 6 UV-vis absorption spectra of naphthalene-containing PI films.

aromatic PI named Kapton ${ }^{\circledR}\left(390^{\circ} \mathrm{C}\right)$. As discussed above, BAN-2 based PI series also have excellent solubility and are soluble in multiple common organic solvents at room temperature. Thus, BAN-2 based PIs may be considered attractive and promising materials from an industrial standpoint because they possess excellent thermal stability and solubility, and in addition the synthesis of their diamines is relatively simple and inexpensive.

In addition, CTE data of PIs was tested by TMA which estimates the size stability of the material upon heating. The CTE value is related to the rigidity and the intermolecular interactions of the polymeric chain. Obviously, BAN-2 based PIs showed relatively lower CTE data than BAN-1 and BAN-3 based PIs did. This may be because the methyl group limits the rotation of the $\mathrm{C}-\mathrm{N}$ bond, thus leading to increase the rigidity. Especially, PI-2B composed of rigid BDPA dianhydride and BAN-2 diamine had the lowest CTE value of $48.03 \mathrm{ppm}{ }^{\circ} \mathrm{C}^{-1}$. However, the bulky isopropyl group of BAN-3 would decrease the intermolecular interactions, which is harmful to the CTEs. So, the CTE value of naphthalene-containing PIs follows this order: BAN-3 > BAN-1 > BAN-2 when using the same dianhydride. This is accordance with the above DSC and TGA results of PIs.

\section{Transparency of naphthalene-containing PIs}

The optical transparency of PI films in the visible region is considered to be a crucial factor in optoelectronic applications.

Table 4 Optical properties of naphthalene-containing PI films

\begin{tabular}{lllll}
\hline PIs & Thickness $(\mu \mathrm{m})$ & $\lambda_{\text {cut-off }}{ }^{a}(\mathrm{~nm})$ & $T_{400 \mathrm{~nm}}{ }^{b}(\%)$ & $\left.T_{450 \mathrm{~nm}^{c}}{ }^{c} \%\right)$ \\
\hline PI-1O & 21 & 371 & 41 & 78 \\
PI-2O & 17 & 345 & 80 & 85 \\
PI-3O & 24 & 346 & 83 & 87 \\
PI-1F & 24 & 368 & 38 & 80 \\
PI-2F & 20 & 330 & 80 & 85 \\
PI-3F & 24 & 326 & 85 & 88 \\
PI-1B & 23 & 401 & 0 & 62 \\
PI-2B & 25 & 376 & 60 & 84 \\
PI-3B & 18 & 361 & 79 & 86
\end{tabular}

${ }^{a}$ Cut-off wavelength. ${ }^{b}$ Transmittance at $400 \mathrm{~nm} .{ }^{c}$ Transmittance at $450 \mathrm{~nm}$. 
Table 5 Mechanical properties of naphthalene-containing PI films ${ }^{a}$

\begin{tabular}{llll}
\hline PIs & $T_{\mathrm{S}}(\mathrm{MPa})$ & $T_{\mathrm{M}}(\mathrm{GPa})$ & $E_{\mathrm{B}}(\%)$ \\
\hline PI-1O & 53.8 & 2.3 & 3.2 \\
PI-2O & 77.2 & 2.5 & 3.9 \\
PI-3O & 64.9 & 1.7 & 4.6 \\
PI-1F & 64.8 & 2.5 & 3.4 \\
PI-2F & 78.1 & 2.7 & 3.7 \\
PI-3F & 87.4 & 2.2 & 5.9 \\
PI-1B & 70.3 & 2.7 & 3.4 \\
PI-2B & 91.9 & 2.8 & 4.7 \\
PI-3B & 68.9 & 2.7 & 3.2
\end{tabular}

${ }^{a} T_{\mathrm{S}}$ : tensile strength, $T_{\mathrm{M}}$ : tensile modulus, $E_{\mathrm{B}}$ : elongation at break.

Generally, due to intra- or intermolecular CTC formation, aromatic PI films exhibit pale yellow to deep brown coloration, depending on the molecular structure. Fig. 6 shows the UV-vis absorption spectra of all the PI films, and the data present in Table 4 . The cutoff wavelength ( $\left.\lambda_{\text {cut-off }}\right)$ of all the PIs derived from BAN-2 and BAN-3 was below $400 \mathrm{~nm}$, which explains why these films were almost colorless. Meanwhile, BAN-2 and BAN-3 based PIs exhibited good optical transparency, whose transmittances exceeded $84 \%$ at $450 \mathrm{~nm}$. Obviously, when compared with PIs derived of the same dianhydride, the transmittance data of BAN-3 based PIs was the highest while the data of BAN-1 based PIs was the lowest. These results clearly indicate that the introduction of side groups into the ortho-positions of the imide nitrogen significantly improve the transparency of PI films. Moreover, the transmittances were enhanced with increasing the steric hindrance of the aliphatic substituent. Therefore, the optical transparency of naphthalenecontaining PIs follows this order: BAN-3 > BAN-2 > BAN-1.

\section{Mechanical properties of naphthalene-containing PIs}

The mechanical properties of the PI films including tensile strength, tensile modulus as well as elongation at break are summarized in Table 5. All the PIs exhibited good tensile strengths above $64 \mathrm{MPa}$ except for the PI-1O polymer, and modulus values of 1.7-2.8 GPa. The elongations at break of the PIs are between $3.2-5.9 \%$. Compared with BAN-1 and BAN-3 based PIs of the same dianhydride, BAN-2 based PIs exhibits stronger tensile strength, higher modulus and longer elongation at break. This is related to the relatively high intrinsic viscosity of BAN-2 based PIs as listed in Table 1.

\section{Conclusions}

In conclusion, this work demonstrates the synthesis of soluble and optically transparent PIs without sacrificing their excellent thermal properties by simultaneously introducing a suitable alkyl group and a naphthalene unit into the diamine monomer. Three kinds of naphthalene-containing diamines with $-\mathrm{H},-\mathrm{CH}_{3}$ or $-\mathrm{CH}\left(\mathrm{CH}_{3}\right)_{2}$ groups substituted at the ortho-positions of the aniline ring were obtained in a simple, inexpensive and highyielding way. Following this, a series of PIs with an intrinsic viscosity above $0.6 \mathrm{dL} \mathrm{g}^{-1}$ were prepared under a highly efficient microwave-assisted polymerization between the diamines and three commercial dianhydrides. Most of these PIs were readily soluble in various polar or non-polar solvents at room temperature, and BAN-2 and BAN-3 based PIs possessed good optical transparency $\left(T_{450} \mathrm{~nm}>84 \%\right)$. Moreover, it was found that the ability of the alkyl groups to improve the solubility and optical transparency of the PIs followed this order: $-\mathrm{CH}\left(\mathrm{CH}_{3}\right)_{2}>-\mathrm{CH}_{3}>$ $-\mathrm{H}$. In addition, all the PIs exhibited high thermal stability $\left(T_{\mathrm{g}}>\right.$ $290{ }^{\circ} \mathrm{C}$ and $T_{5 \%}$ weight loss $>510{ }^{\circ} \mathrm{C}$ ). What is more, PI-2B composed of BAN-2 and BPDA maintained excellent thermal properties which was comparable with the conventional PI material, as well as possessed good solubility and optical transparency. Therefore, the simultaneous introduction of suitable aliphatic and aromatic units into the same monomer can offer an opportunity to prepare high-temperature PI materials with excellent solution processability and optical transparency.

\section{Acknowledgements}

We gratefully acknowledge the financial support from National Basic Research Program of China (no. 2014CB643600), Guangdong Innovative and Entrepreneurial Research Team Program (no. 2013S086), and Natural Science Foundation of Guangdong Province (2014A030312018).

\section{Notes and references}

1 T. Hasegawa and K. Horie, Prog. Polym. Sci., 2001, 26, 259335.

2 H. J. Ni, J. G. Liu, Z. H. Wang and S. Y. Yang, J. Ind. Eng. Chem., 2015, 28, 16-27.

3 L. Yi, W. Huang and D. Y. Yan, J. Polym. Sci., Part A: Polym. Chem., 2017, 55, 533-559.

4 F. W. Harris, S.-H. Lin, F. Li and S. Z. D. Cheng, Polymer, 1996, 37, 5049-5057.

5 M. G. Dhara and S. Banerjee, Prog. Polym. Sci., 2010, 35, 1022-1077.

6 W. Huang, D. Y. Yan and Q. H. Lu, Macromol. Rapid Commun., 2001, 22, 1481-1484.

7 D.-J. Liaw, F.-C. Chang, M.-k. Leung, M.-Y. Chou and K. Muellen, Macromolecules, 2005, 38, 4024-4029.

8 P. K. Tapaswi, M.-C. Choi, K.-M. Jeong, S. Ando and C.-S. Ha, Macromolecules, 2015, 48, 3462-3474.

9 Y. Z. Guo, H. W. Song, L. Zhai, J. G. Liu and S. Y. Yang, Polym. J., 2012, 44, 718-723.

10 G. C. Eastmond, J. Paprotny, R. A. Pethrick and F. Santamaria-Mendia, Macromolecules, 2006, 39, 7534-7548.

11 R. Hariharan, S. Bhuvana, N. Amutha and M. Sarojadevi, High Perform. Polym., 2006, 18, 893-905.

12 X. H. Huang, W. Huang, J. Y. Liu, L. L. Meng and D. Y. Yan, Polym. Int., 2012, 61, 1503-1509.

13 R. Hariharan and M. Sarojadevi, J. Appl. Polym. Sci., 2006, 102, 4127-4135.

14 X. H. Huang, M. Mei, C. J. Liu, X. L. Pei and C. Wei, J. Polym. Res., 2015, 22, 1-9. 
15 C.-Y. Wang, G. Li, X.-Y. Zhao and J.-M. Jiang, J. Polym. Sci., Part A: Polym. Chem., 2009, 47, 3309-3317.

16 L. Y. Wang, P. L. Chang and C. L. Cheng, J. Appl. Polym. Sci., 2006, 100, 4672-4678.

17 C.-S. Wang, T.-S. Leu and K.-R. Hsu, Polymer, 1998, 39, 29212927.
18 K. Kempe, C. R. Becer and U. S. Schubert, Macromolecules, 2011, 44, 5825-5842.

19 C.-S. Wang and T.-S. Leu, Polymer, 2000, 41, 3581-3591.

20 C. J. Liu, X. L. Pei, X. H. Huang, C. Wei and X. Y. Sun, Chin. J. Chem., 2015, 33, 277-284. 